Int. J. Electrochem. Sci., 15 (2020) 10058 - 10080

International Journal of

ELECTROCHEMICAL

SCIENCE

WWW.electrochemsci.org

\title{
Inhibition Synergism Between Alkyl Imidazoline and Potassium Iodide on the Corrosion of Carbon Steel in Citric Acid Solution
}

Jianjia Shen, Yaqiong Chen, Yitong Tan, Dong Yang, Xinxin Liu, Zesong Gao and Qiangqiang Liao*

Shanghai Engineering Research Centre of Heat-Exchange System and Energy Saving, Shanghai Key Laboratory of Materials Protection and Advanced Materials in Electric Power, Shanghai University of Electric Power, Shanghai 200090, China

*E-mail: liaoqianqiang@shiep.edu.cn

doi: $10.20964 / 2020.10 .23$

Received: 4 May 2020 / Accepted: 17 July 2020 / Published: 31 August 2020

The synergistic inhibition effect of the complex of 2-undecyl-N-carboxymethyl-N-hydroxyethly imidazoline (UHCI) and potassium iodide (KI) on the corrosion of 45\# carbon steel subjected to 4 wt.\% citric acid solution is explored by weight loss testing, electrochemical measurement, and X-ray photoelectron spectroscopy (XPS) analysis. Based on the weight loss test, $94.15 \%$ inhibition capacity is obtained by compound inhibitors (UHCI:KI=30:10) after immersion in $4 \mathrm{wt} . \%$ citric acid for $8 \mathrm{~h}$, which is consistent with the results from electrochemical technology. The discussion extends to the effects of temperature and immersion time to achieve the ideal inhibition performance for further protection. The adsorption of the studied compound fitted well with the Langmuir isotherm model. The XPS analysis confirms physical and chemical interactions between the UHCI/KI complex inhibitors and metal surface to defend the aggressive electrolyte. Additionally, the corrosion inhibition mechanism of UHCI inhibitor in the presence of iodine ions in the citric acid solution is discussed.

Keywords: Carbon steel; Corrosion inhibitor; Synergism; EIS; XPS.

\section{FULL TEXT}

(C) 2020 The Authors. Published by ESG (www.electrochemsci.org). This article is an open access article distributed under the terms and conditions of the Creative Commons Attribution license (http://creativecommons.org/licenses/by/4.0/). 